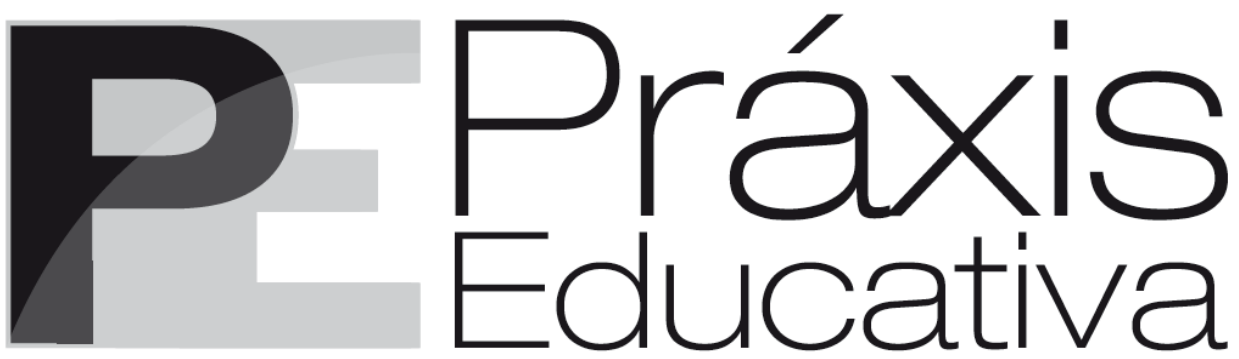

ISSN 1809-4031

elSSN 1809-4309

https://doi.org/10.5212/PraxEduc.v.15.14812.040

\title{
Educação domiciliar, diferença e construção do conhecimento: contribuições para o debate
}

\section{Homeschooling, difference and knowledge construction: contributions to the debate}

\section{Educación domiciliaria, diferencia y construcción del conocimiento: contribuciones al debate}

Caroline Becker https://orcid.org/0000-0003-2735-1110

Katlen Bohm Grando * https:/ / orcid.org/0000-0001-8703-0269

Morgana Domênica Hattge ${ }^{* \star}$

(iD) https://orcid.org/0000-0002-4716-0410

\begin{abstract}
Resumo: O propósito deste artigo é contribuir com o debate acerca da educação domiciliar no contexto brasileiro, por meio de um ensaio teórico. Nesse sentido, apresenta-se, por um lado, os principais argumentos a favor da prática; e, por outro, aspectos que fundamentam a escola como um espaço de possibilidade de reconhecimento da diferença e de igualdade. Importa refletir acerca da relevância da relação com o outro para a construção do conhecimento. Assim, este texto apoia-se em Vygotsky e no conceito cunhado por ele de Zona de Desenvolvimento Proximal. Para efeitos de conclusão, considera-se a importância de um debate amplo, sólido, em que as especificidades familiares, sociais e cognitivas de cada criança sejam consideradas no que tange ao planejamento e à ação de medidas que envolvam a educação no Brasil.

Palavras-chave: Homeschooling. Diferença. Construção do conhecimento. Aprendizagem. Vygotsky.
\end{abstract}

Abstract: The purpose of this paper is to contribute to the debate concerning homeschooling in Brazil, through a theoretical essay. In this sense, on the one hand, the main arguments in favor of the practice are

\footnotetext{
* Orientadora Educacional do Colégio Marista Rosário (Porto Alegre - RS). Doutora em Educação pela Pontifícia Universidade Católica do Rio Grande do Sul (PUC/RS). E-mail: < carolbeckerr@gmail.com>.

** Coordenadora Pedagógica do Colégio Marista PIO XII (Novo Hamburgo -RS). Doutora em Educação pela Universidade Federal de Peltos (Ufpel).E-mail: <katlengrando@gmail.com>.

*** Professora na Universidade do Vale do Taquari - Univates (Lajeado - RS). Doutora em Educação pela Unisinos. Email: <mdhattge@univates.br>.
} 
presented; and, on the other hand, aspects that support the school as a space for the possibility of recognizing difference and equality. It is important to reflect on the relevance of the relationship with the other for the construction of knowledge. Thus, this text relies on Vygotsky and the concept of Proximal Development Zone coined by him. In conclusion, the importance of a broad, solid debate is considered, in which the family, social and cognitive specificities of each child are considered with regard to the planning and action of measures involving education in Brazil.

Keywords: Homeschooling. Difference. Knowledge building. Learning. Vygotsky.

Resumen: El propósito de este artículo es contribuir al debate sobre la educación domiciliaria en el contexto brasileño, por medio de un ensayo teórico. En este sentido, se presentan, por un lado, los principales argumentos a favor de la práctica; $y$, por otro lado, aspectos que fundamentan a la escuela como un espacio para la posibilidad de reconocimiento de la diferencia y de igualdad. Importa reflexionar sobre la relevancia de la relación con el otro para la construcción del conocimiento. Así, este texto se apoya en Vygotsky y en el concepto acuñado por él de Zona de Desarrollo Proximal. Como conclusión, se considera la importancia de un debate amplio y sólido, en el que las especificidades familiares, sociales y cognitivas de cada niño sean consideradas con respecto a la planificación y a la acción de medidas relacionadas con la educación en Brasil.

Palabras-clave: Homeschooling. Diferencia. Construcción del conocimiento. Aprendizaje. Vygotsky.

\section{Introdução}

É visível, no contexto brasileiro, o crescimento de um grupo de famílias que discorda dos modelos de educação assumidos pela maior parte das escolas do nosso país, sejam elas públicas ou privadas. Frente a esse descontentamento e, diante da facilidade atual em conhecer novas propostas, essas famílias se negam a inserir seus filhos no modelo escolar vigente. Elas passam, então, a buscar alternativas, formais ou informais, que atendam às suas expectativas. Essas alternativas incluem movimentos de creche parental, a criação de associações e/ou escolas com propostas diferenciadas, dentre outras.

Um movimento que vem instigando estudiosos da educação é a possibilidade de legalização da educação domiciliar no Brasil, por meio do Projeto de Lei 2401/2019 (BRASIL, 2019b). Diante de tantas controvérsias em relação à proposta, cabe o posicionamento dos especialistas para que se promova uma reflexão sobre o entendimento de que à escola cabe um papel crucial no desenvolvimento do educando, o qual transcende o reducionismo da aquisição de conteúdo.

Nesse sentido, o propósito deste artigo é apresentar aspectos que fundamentam a escola como um espaço de desenvolvimento de socioemocional, de possibilidade de reconhecimento da diferença e de igualdade, bem como refletir acerca da importância da relação com o outro para a construção do conhecimento. Desse modo, na primeira seção, apresentamos a escola como um lugar de possibilidade, de manifestação da diferença e espaço que se organiza pelo princípio da igualdade. Na segunda seção, argumentamos acerca da importância do outro para a construção do conhecimento, nos apoiando em Vygotsky e no conceito, cunhado por ele, de Zona de Desenvolvimento Proximal (ZDP). Para efeitos de conclusão, consideramos a escola como lócus privilegiado para o desenvolvimento socioemocional e cognitivo, na medida em que promove a interação entre o eu e o outro. Salientamos que não nos importa encerrar a discussão, mas, pelo contrário, ampliar o debate, de modo a colaborar para o planejamento de medidas educativas em nosso país. 


\section{A escola como lugar de possibilidade, de diferença e de igualdade}

A escola moderna - essa que se tornou nacional, obrigatória, praticamente universal - é vista, muitas vezes, como a instituição responsável por preparar as crianças e os jovens para o mundo do trabalho. E, se esse for o principal objetivo da escola, podemos perguntar-nos se ela ainda teria razão de ser, dado que vivemos em uma sociedade cambiante, em que os contextos de produção do conhecimento e o avanço tecnológico tornam quase impossível inferir que profissional seria esse a ser formado pela escola para um futuro que se localiza 15 ou 20 anos à frente. Assim sendo, nos últimos tempos, tem crescido o número de famílias interessadas na educação domiciliar (homeschooling).

No Brasil, a educação domiciliar não é regulamentada e as famílias interessadas em adotar essa prática precisam de autorização judicial, uma vez que a matrícula e a frequência de crianças de 4 a 17 anos na escola é obrigatória, sendo considerada na legislação como um direito da criança e obrigação do Estado e da família (BRASIL, 1990). Desse modo, os responsáveis respondem criminalmente no caso do não cumprimento dessa obrigatoriedade.

Diante disso, tramita na Câmara Federal o Projeto de Lei 2401/2019, que dispõe sobre o direito à educação domiciliar, alterando, portanto, a Constituição Federal e o Estatuto da Criança e do Adolescente. O referido PL (Brasil, 2019) propõe que os pais ou responsáveis legais tenham o direito de escolher o tipo de instrução a ser ministrada aos seus filhos e refere-se à educação domiciliar como um regime de ensino de crianças e de adolescentes, dirigido pelos seus pais ou responsáveis legais.

Vasconcelos e Boto (2020), ao realizarem estudo detalhado mostrando os diferentes Projetos de Lei que tramitam na Câmara Federal e no Senado desde o ano de 2000, mostram que um dos principais argumentos para a prática do ensino domiciliar seria a má qualidade do ensino ministrado nas escolas públicas do país. Nessa perspectiva, vale perguntar: De que qualidade estamos falando? Trata-se da qualidade que pode ser aferida em avaliações de larga escala? Uma qualidade passível de ser rankeada? Nesta seção, queremos argumentar em favor de uma outra função da escola que acaba por ser desconsiderada no caso de uma prática de educação domiciliar: a escola como lugar de possibilidade, de diferença e de igualdade.

[...] a escola se apresenta como uma clareira, um espaço público, separado das urgências do mundo produtivo, onde a sociedade pode se relacionar consigo mesma, sem as urgências nem demandas da vida cotidiana. Nisso consiste seu valor político, em reaprender o mundo sob o signo da possibilidade. (LÓPEZ; MASSCHELEIN; SIMONS, 2017, p. 187).

Contudo, que possibilidades seriam essas? Quem pode dizer? Se entendermos a escola como o lugar da igualdade, essa suspensão do tempo, proposta por Masschelein e Simons (2013), podemos vê-la também como um espaço da diferença. E a diferença, nesse caso, é importante dizer, nada tem a ver com as políticas de inclusão ${ }^{1}$. Quando trazemos para a discussão esse termo não o compreendemos como sinônimo de diversidade, mas diferença como a singularidade que nos constitui a todos e a cada um. Nesse sentido, estamos falando da multiplicidade de modos de ser, de aprender, de conviver, passíveis de se constituírem. E talvez não haja espaço mais profícuo para a manifestação dessa diferença do que o espaço da escola. Espaço em que os sujeitos

\footnotetext{
${ }^{1}$ Com todo o respeito que temos para com as políticas de inclusão e ativistas que somos por uma escola cada vez mais inclusiva, é importante aqui fazer essa ressalva. Entendemos que os esforços em prol de incluir todos na escola são necessários e urgentes, mas, neste texto, estamos tratando da noção de escola como espaço da diferença em outro sentido: um sentido que considera cada sujeito como único e a diferença como a marca dessa singularidade que, ao mesmo tempo, é a responsável pela pluralidade que se faz presente no espaço escolar e que torna tão complexa a tarefa da escola.
}

Práxis Educativa, Ponta Grossa, v. 15, e2014812, p. 1-12, 2020 Disponível em: <http://www.revistas2.uepg.br/index.php/praxiseducativa> 
convivem, no mínimo, por quatro horas diárias, cinco dias da semana e durante um período de 200 dias letivos ao longo de um ano.

Se entendemos a diferença como essa singularidade que nos constitui, para que ela seja passível de ser conhecida, compreendida, aceita ou não, é preciso dar-se o tempo de conhecer; sem convivência não há acesso à diferença. Convivendo por alguns momentos em um parque, um clube, uma escola de idiomas, podemos perceber a diversidade de cada sujeito: alguns mais baixos, outros mais altos; alguns brancos, outros negros; alguns gordos, outros magros; alguns com e outros sem deficiência; todas essas características possíveis de serem acessadas pelo olhar, em um contato inicial, em uma conversa corriqueira, são da ordem da diversidade. Para que se possa ter acesso à diferença, é preciso se aproximar mais, é preciso tempo, é preciso ver o outro como sujeito único.

Biesta (2017) recupera Hannah Arendt para argumentar que: "Precisamos dos outros, de outros que respondam a nossas iniciativas, que adotem nossos inícios, para que sejamos capazes de agir e, consequentemente, sejamos um sujeito. Isso também significa [...] que a ação nunca é possível sem pluralidade" (BIESTA, 2017, p. 175). Para muito além do fato de simplesmente "estar junto" em um mesmo espaço, estar em contato com indivíduos que reagem de forma diferente aos "nossos inícios", coloca-nos em contato com a pluralidade. Isso nos possibilita também reagir aos inícios colocados por outros, de modo a nos confrontar com as nossas verdades, forjadas no seio de nossa cultura familiar, e nos abrir a novas possibilidades, por vezes impensadas sem essa abertura ao outro/aos outros e ao seu início/aos seus inícios. Acreditamos que seja possível ampliarmos nosso horizonte de análise e inserirmos também a própria família nessa lógica.

Quando a família manifesta seu desejo por inserir seus filhos em uma proposta de educação domiciliar, isso nos diz de seu desejo de um maior controle do processo educacional ao qual estarão submetidos. Casagrande e Hermann (2020, p. 2) explicam que "[...] em sua maior parte, o debate em torno do homeschooling vincula-se ao princípio da liberdade de escolha dos pais em educar seus filhos". Ao fazer essa escolha, as famílias projetam uma formação que se relaciona intimamente com a cultura familiar, com os anseios de vida dos pais, ou com desejos já manifestos das crianças.

Entretanto, em contrapartida, quando se analisa a inserção dessa díade criança/família no espaço da escola, é interessante analisar que, como instituição social com suas regras, demandas, cultura muito próprias, cada família que adentra nesse espaço também coloca para essa comunidade escolar que se organiza os "seus inícios" e passa a receber as respostas de outrem a suas iniciativas. De igual maneira, vê-se diante dos inícios de outras famílias, estudantes, professores e reage a eles de diferentes formas. Assim sendo, cada família que se inclui no ambiente escolar se depara e é confrontada com elementos diversos daqueles pensados, propostos e validados por si. Esses elementos tornam-se importantes na medida em que provocam um pensar sobre seus próprios valores e atitudes. Esse pensar, por sua vez, pode levar a modificações, ressignificações e confirmações dos "seus inícios".

Não nos propomos, evidentemente, a assumir uma visão romantizada da escola, acreditando que a simples inserção nesse espaço seja capaz de garantir aprendizagem social, democrática e plural a todos. No entanto, vemos a escola como esse lugar de possibilidade, especialmente àquelas famílias que se abrem ao verdadeiro diálogo gadameriano. Gadamer (2002), ao refletir sobre o diálogo, acreditava que ele teria uma força transformadora, uma vez que possibilitava a construção de algo que não existia antes do diálogo acontecer. Quando duas pessoas se encontram e se abrem ao diálogo, trata-se do encontro entre dois mundos distintos, entre dois diferentes inícios. O diálogo, então, representa a expansão da individualidade e deixa marcas naqueles que dele participam, pois é espaço para o novo: novas ideias e percepções que resultam do encontro entre dois inícios. 
Gadamer (2002, p. 251), ao refletir sobre o homem e o diálogo, afirmou que "[...] a capacidade constante de voltar ao diálogo, isto é, de ouvir o outro, parece-me ser a verdadeira elevação do homem a sua humanidade". Tal "ouvir o outro" pressupõe olhar para si também, na medida em que o outro provoca, interrompe, afeta; desse modo, o outro mobiliza um pensar sobre si mesmo. Ao transpor o conceito de diálogo gadameriano às reflexões sobre a educação domiciliar e a educação escolar, é possível entender que os movimentos de interação entre os inícios das diferentes famílias, entre as famílias e a escola e entre os indivíduos, propiciados pela convivência sistemática no contexto escolar, é potente na criação do novo e na ampliação das individualidades, colaborando para a aprendizagem do plural e da diferença.

[...] ser uma pessoa democrática num mundo de pluralidade e diferença, consiste tanto em fazer, falar e introduzir-se no mundo como em escutar e esperar, criando espaços para que os outros comecem, e assim criando oportunidades para que os outros sejam um sujeito. [...] Acarreta, portanto, uma responsabilidade educacional dupla: uma responsabilidade em relação a cada indivíduo e uma responsabilidade em relação "ao mundo", o espaço da diferença e pluralidade como condição para a subjetividade democrática. (BIESTA, 2017, p. 183-184).

E a escola, ao trazer essa possibilidade de vivência democrática, de respeito ao que é plural, de produção da diferença e do novo, estende seu espectro de atuação, em muitos casos, dos estudantes para as suas famílias, conforme já viemos refletindo. Considerando os aspectos elencados anteriormente, relativos às potencialidades da escola como lócus privilegiado de possibilidade, de diferença e de igualdade, cabe refletir acerca da não inserção de famílias e de crianças nesse contexto.

De acordo com o presidente da Associação Nacional de Estudos Domiciliares, Rick Dias², cerca de um quarto das famílias que retiram as crianças das instituições formais de ensino e optam pelo ensino domiciliar, apresentam como justificativa questões ligadas à “[...] má socialização escolar" (BRASIL, 2019a, n.p.), o que nos faz compreender que se tratam de crianças que não se adaptaram ao contexto escolar em função da má interação com os colegas ou professores, falta de sentimento de pertença, bullying, conflitos, dentre outros. Diante disso, poderíamos questionar se, em vez de retirar a criança da situação conflituosa, não seria mais construtivo auxiliar na construção de elementos que possibilitassem a superação dos desafios. No entanto, acreditamos que cada situação deva ser considerada em seu contexto.

Ainda assim é possível e necessário refletir sobre o papel da escola no que diz respeito ao desenvolvimento socioemocional. Defensores dos estudos domiciliares afirmam que é frágil o argumento de que a escola deva ser defendida em função da convivência entre pares. Isso pelo fato de que, em países onde o ensino domiciliar é regulamentado, faz parte da carga horária semanal momentos de interação e de convivência, o que pode ser garantido quando a criança participa de oficinas ou brincadeiras em espaços públicos. Nesse sentido, o PL 2401/2019 apenas cita, como dever dos pais ou responsáveis que optarem pela educação domiciliar, assegurar a convivência familiar e comunitária. Assim sendo, de acordo com os defensores da educação domiciliar, essas crianças teriam possibilidade de interagir com uma gama ainda mais diversa de crianças, grupos sociais e etários do que aquelas que convivem prioritariamente com seus colegas de classe. Entretanto, como já citamos, essa convivência eventual garante o acesso à diversidade, não à diferença.

Reconhecendo a importância da inserção das crianças no contexto escolar para a garantia da vivência com a diferença e o desenvolvimento socioemocional, nossa perspectiva vai além desse

\footnotetext{
${ }^{2}$ Declaração expressa em entrevista televisiva transmitida pela TV Câmara, em 9 de abril de 2019, disponível em: <https://www.youtube.com/watch?v=fZ0EMETPMhQ>. Acesso em: 2 abr. 2020.
} 
entendimento e compreende a necessidade da convivência sistemática com os pares para a própria construção do conhecimento; dessa maneira, sustenta-se na ideia de que o outro tem papel crucial na apreensão e na consolidação da aprendizagem.

\section{O outro e a construção do conhecimento}

Não é nova a noção de que a aprendizagem é um processo individual. Os recentes estudos das Neurociências (BEAR; CONNORS; PARADISO, 2002; COSENZA; GUERRA, 2011; ROSSA; ROSSA, 2011) ajudam a explicar todo esse processo envolvido na aprendizagem, que engloba atividades cruciais como a atenção, a motivação e a memória, além, evidentemente, dos aspectos anatômicos e fisiológicos. Em paralelo a esses processos individuais, o outro detém um papel crucial para a aprendizagem, e isso ocorre na medida em que o outro exerce diferentes funções: ora como aquele que desafia ou interrompe, ora como aquele que auxilia.

Biesta (2017) propõe a seus leitores que pensem em uma pedagogia da interrupção e, nesse sentido, afirma que é parte da responsabilidade educacional propor situações que propiciem a “interrupção do ser de um ser" (BIESTA, 2017, p. 194). Desse modo, o autor afirma que o professor, ao propor perguntas nas quais os estudantes são desafiados a sair da sua zona de conforto, estão colaborando para uma mudança de paradigma: "[...] a educação deixa de ser um processo de dar algo e torna-se um processo de perguntar, um processo de formular perguntas difíceis" (BIESTA, 2017, p. 195).

Pode-se pensar sobre qual seria a importância dessas perguntas. Segundo o pensamento do autor, ao deparar-se com essas perguntas, o aluno é interrompido como ser e pode mostrar-se como alguém único. Portanto, o papel do professor como aquele que desafia é potencializador de novas construções por parte do aluno. Nessa linha, podemos pensar que o outro, o colega, também pode representar a interrupção na medida em que, ao representar "novos inícios", desestabiliza, desafia, provoca.

Um dos grandes nomes da teoria do desenvolvimento fundamentada no sociointeracionismo e referência das propostas pedagógicas em grande parte das instituições de ensino no Brasil é Vygotsky. Segundo Guilherme e Morgan (2018), Vygotsky desenvolveu sua teoria com o foco na contribuição da cultura, interação social e a dimensão histórica do desenvolvimento mental humano, perspectiva que se vincula à ideia de que estamos discutindo as implicações da interação social nos processos cognitivos.

Nesse propósito, cabe ressaltarmos uma importante influência no pensamento de Vygotsky, destacada por Guilherme e Morgan (2018): a de Ivan Pavlov (1849-1936), já que a psicofisiologia pavloviana forneceu a base materialista para o estudo da mente, ao deixar Vygotsky impressionado, fazendo-o concordar que as respostas condicionais (reações adquiridas) emergem de respostas incondicionais (reações inatas) e que o ambiente era um aspecto determinante para o desenvolvimento. Contudo, Vygotsky acreditava que a formação de reflexos condicionais não poderia explicar completamente o desenvolvimento dos processos mentais superiores, tais como a fala e a resolução de problemas: a noção corrente de maturação como processo passivo não pode descrever, de forma adequada, os fenômenos complexos (VYGOTSKY, 2007, p. 4). Para o teórico, o comportamento humano se distingue dos animais, na perspectiva da psicologia, por meio da significação, ou seja, pela criação e pelo uso de sinais, como, por exemplo, a fala. Guilherme e Morgan (2018) afirmam que o behaviorismo de Pavlov, o condicionamento clássico e sua aprendizagem por associação, é, segundo Vygotsky, simplista demais para explicar níveis mais elevados de pensamento e de aprendizado. 
Em sua teoria, Vygotsky propôs que o desenvolvimento ocorre primeiro por meio da maturação orgânica, mas que também envolve compreender os mecanismos de pensamento e o comportamento culturalmente apropriado e condicionado, isto é, o desenvolvimento natural tornase o desenvolvimento social: "[...] o aprendizado humano pressupõe uma natureza social específica e um processo através do qual as crianças penetram na vida intelectual daqueles que a cercam" (VYGOTSKY, 2007, p. 100). Funções primárias, como, por exemplo, a atenção, a memória e a percepção, tornam-se funções superiores, dependendo da qualidade da interação e dos elementos sociais e culturais aos quais o sujeito é submetido. Nesse aspecto, entendemos que o ensino no espaço escolar poderá potencializar a cognição por meio da interação com os pares, nos processos de construção do conhecimento, ampliando oportunidades do desenvolvimento da criança, na medida em que ela frequenta um ambiente rico em diversidade e no qual se depara com a diferença e a singularidade que nos constitui como sujeitos, como argumentamos anteriormente. Nesse ambiente, precisa confrontar, debater, construir, aprender, desenvolver estratégias para as relações que se estabelecem pelo e no convívio social.

Ao transpormos essa reflexão para o ensino domiciliar, mesmo considerando o tempo previsto de interação social da criança com seus pares, na aprendizagem formal, essa mesma criança, provavelmente, contará com um número restrito de pessoas acompanhando - ou promovendo possibilidades para - o seu processo de aprendizagem. Dessa forma, ficará restrita às experiências oportunizadas na intimidade do seu lar, compartilhando com algumas pessoas certamente um número reduzido em relação ao espaço escolar - experiências sociais, culturais, de linguagem e de compreensão de mundo, o que implica diretamente no desenvolvimento das funções superiores, conforme teoria de Vygotsky.

$\mathrm{Na}$ internalização de processos histórico-culturais externos pelo indivíduo, a linguagem desempenha um papel crucial. A fala é um elemento sociocultural que atua na formação de processos mentais superiores. São as palavras e os signos que representam, que constituem o principal meio de contato entre o sujeito e o mundo social. O discurso de uma criança é tão importante quanto o papel da ação para atingir o objetivo. As crianças não apenas falam sobre o que estão fazendo, mas fala e ação fazem parte de uma mesma e complexa função psicológica, direcionada à solução do problema em questão. Quanto mais complexa a ação exigida pela situação, maior será a importância desempenhada pela fala na operação como um todo.

Às vezes a fala se torna de importância tão vital que, se não for permitido usá-la, as crianças pequenas não podem realizar a tarefa dada. Entendemos, novamente, a importância do espaço escolar no desenvolvimento da linguagem, na medida em que a criança e o adolescente são constantemente desafiados a comunicar suas ideias, seus pensamentos, seus desejos e suas necessidades para um grupo diverso em todos os aspectos, interrompendo e sendo interrompido, compartilhando seus inícios e possibilitando tantos outros. Para Vygotsky, o fenômeno da fala começa como uma interação com os outros, o que colabora no desenvolvimento da linguagem.

Para Guilherme e Morgan (2018), a fala é um diálogo que surge quando a criança procura outros para resolver problemas. No entanto, ela é internalizada quando a criança começa a encontrar suas próprias soluções. Isso geralmente aparece como falar para si mesmo, o que pode ser visto quando uma criança está brincando. Como tal, a fala é uma ferramenta para interação social, mas é também um instrumento semiótico para o pensamento. À medida que envelhecemos, essa autofala diminui, tornando-se cada vez mais internalizada, e assume a forma de "fala interior". Essa "fala interior" nunca desaparece, é uma ferramenta para pensar, e sempre que encontramos atividades desconhecidas ou exigentes, essa fala privada ressurge.

Os autores destacam que, para Vygotsky, a fala é extremamente importante tanto como um diálogo com os outros, como autodiálogo, fundamentais em função das implicações que têm para 
uma compreensão filosófica do humano e para a educação, considerando que os seres humanos, em razão de sua origem e natureza, não podem existir, nem desenvolver-se individualmente. Dessa forma, para uma criança se desenvolver, é necessário haver interação com os outros que a introduzirão em sua cultura, por meio de uma rede de relações. Essa interação e esse diálogo, entre a criança e os adultos, transferem ferramentas culturais e signos de uma geração para a seguinte, e esse processo tem um papel formativo crucial na organização e no controle do comportamento e da consciência do indivíduo. Filosoficamente falando, Vygotsky argumenta que não há indivíduo sem comunidade (GUILHERME; MORGAN, 2018). Portanto, as relações com o outro, ou com os outros, são basais para a condição humana e para os processos cognitivos. Segundo a teoria de Vygotsky, não seria possível separar o que é aprendizagem da relação com o outro. Para nós, esse é mais um importante argumento que endossa a amplitude e a riqueza da aprendizagem no espaço escolar, em um encontro de diversos mundos que contribuem na construção de mundos que transitam entre o particular e o coletivo.

No caso do ensino domiciliar, é inegável, portanto, a redução de possibilidades de interação do aprendiz. Retomando o argumento das famílias que justificam a referida opção, por seus filhos estarem expostos a situações conflituosas no ambiente escolar, essas crianças podem estar sendo poupadas justamente de oportunidades de desenvolvimento dos seus processos mentais superiores, ao deixarem de lidar com situações entre pares que demandem posicionamento, tomada de decisão e resolução de conflito.

O pensamento de Vygotsky teve e ainda tem um impacto significativo na educação. $O$ objetivo primário do teórico era entender o surgimento da consciência, o que significa que o papel das interações sociais deve ser entendido como um pano de fundo, nunca como um assunto principal. Propunha que as escolas buscassem reorganizar situações de aprendizagem para possibilitar que os alunos aprendessem como agentes da própria aprendizagem, com as colaborações dos seus pares (VYGOTSKY, 2007). Talvez aqui tenhamos mais um aspecto positivo da educação escolar: a criança pode contar, em seu desenvolvimento cognitivo e psicomotor, com os desafios e as colaborações dos seus pares, demandando a construção de um conhecimento que transcende conteúdo e resulta em habilidades para solucionar problemas das mais diversas ordens.

Para que a aprendizagem ocorra, Vygotsky apresenta o conceito de ZDP, fortalecendo o papel dos outros na construção do conhecimento da criança e do professor no estímulo e no apoio desse processo de aprendizagem. Vygotsky (2007) considerou que a transição do social para o indivíduo implica uma transformação. Para explicar isso, ele elaborou os conceitos de internalização, de ZDP e de mediação. O famoso teórico do construtivismo aborda o ensino e a aprendizagem sob a perspectiva da teoria sociocultural e que deriva de três ideias fundamentais: o aluno é responsável por seu próprio processo de aprendizado; o aluno que constrói seu conhecimento e não pode ser substituído nessa tarefa; os objetos são pré-existentes e aceitos como conhecimento cultural. Isso muda o papel do professor, pois sua atuação não pode limitar-se apenas a criar as condições ideais para que os alunos realizem sua própria construção mental rica e diversa, mas, sim, gerenciar e orientar a atividade dos alunos de tal forma que eles compreendam progressivamente os significados e as representações da cultura.

Tal orientação ocorre por meio da ZPD, estabelecendo o que o aluno já sabe e o que deve ser aprendido com a ajuda do outro. Essa interpretação está desconectada do problema da transmissão do conhecimento acadêmico e torna a ZDP um espaço social em que as ações do professor e dos pares são interpretadas como uma atividade de compartilhamento que orienta a descoberta da criança em relação ao objeto do conhecimento. Assim, o foco em ambientes ricos de ensino demanda de respeito aos diferentes tempos de aprendizado dos alunos e a presença de 
um mediador nessa aprendizagem, um outro sujeito com mais conhecimento do assunto em questão (VYGOTSKY, 2007).

Para Guilherme e Morgan (2018), o reconhecimento de que os alunos aprendem em velocidades diferentes, têm interesses diversos e possuem uma variedade de aptidões caracteriza ações a serem planejadas e executadas pelo docente. Portanto, compreender professores e agentes de ensino, ou, até mesmo pais, como simples facilitadores da aprendizagem da criança, é inconsistente com o trabalho de Vygotsky. Entendemos que o profissional responsável pela aprendizagem necessita bem mais do que boa vontade para atuar, tampouco ele dará conta desse processo de forma individual.

Mais um ponto de destaque para o ensino no espaço escolar, pautado nas teorias apresentadas, é a rede de profissionais habilitados que atuam para que os alunos tenham a oportunidade de serem acompanhados por um olhar holístico e pluricultural. Há uma série de conhecimentos, que transcendem o conteúdo, necessários para que se possa ensinar e aprender e este deve ser um empreendimento compartilhado pelos diferentes atores envolvidos nos processos de ensino e de aprendizagem: professores e alunos. Ambos, usando conteúdo pertinente apropriado, são responsáveis pelo processo. Isso não significa uma perfeita simetria entre eles, pois o professor e o aluno desempenham papéis diferentes, embora sejam entendidos como essencialmente interconectados. Nesse processo, sempre há troca de conhecimentos, pois ora o aluno, ora o professor, detém mais ou diferentes conhecimentos, relativos à determinada temática. E é nessas diferenças, encontros e significações que a escola se estabelece e que entendemos que a aprendizagem é potencializada.

Se a experiência serve como base para novos conhecimentos e é obtida por meio da mediação de um outro com mais conhecimento, por meio da ZPD, a base para tal mediação é o diálogo. Nesse contexto, o diálogo, conforme proposto por Gadamer (2002), se constitui como um intercâmbio entre os conhecimentos daqueles que se propõem a dialogar. Tendo conhecimentos diferentes, o diálogo propicia a construção de algo diferente. Esse movimento é construtivo para todos os que dele participam, mas, especialmente, para aquele que está em um processo de aprendizagem intencional, pois ele será interrompido a partir da fala daquele que sabe mais, pois este último apresenta ideias diferentes, hipóteses mais avançadas, ideias mais aprofundadas. Assim, desse diálogo, o aluno avança naquilo que sabia inicialmente. O outro, então, representa aquele que auxilia no processo de construção do conhecimento.

Para Guilherme e Morgan (2018), a principal responsabilidade do educador é ser um filtro do mundo para o aluno, que transcende a ideia do simples processamento, da transmissão e do armazenamento de informações. Isso significa que no diálogo pedagógico deve haver assimetria intrínseca. Ser um filtro significa permitir o fluxo de certos tipos de interação com o mundo e desestimular outros. Ao mesmo tempo, enquanto o aluno procura tanto quanto possível a experiência do mundo sem quaisquer limites, o educador esforça-se para selecionar experiências.

Portanto, o ensino e a aprendizagem devem capacitar os alunos a realizarem a tarefa que eles não teriam conseguido administrar sozinhos, tendo como objetivo levá-los a um estado de competência que lhes permita, por fim, concluir as tarefas por conta própria, demonstrando evidências de que alcançaram algum nível maior de competência. Na perspectiva da ZPD, portanto, toma-se de importância fundamental o diálogo, tanto externo (com os outros), quanto interno (fala interior, consigo mesmo), para o sucesso do ensino e da aprendizagem e, consequentemente, para o aprendizado e para a transformação do indivíduo e da sociedade.

Considerando a ZDP, se, por um lado, o ensino domiciliar poderia representar benefícios no que diz respeito à maior facilidade em reconhecer o que o aluno já sabe e o que consegue fazer 
com a ajuda do outro, por tratar-se de um número reduzido ou único de alunos; por outro lado, a possibilidade de interação desse aluno com outros, sejam eles professores ou colegas, para o avanço de suas hipóteses e construções, é limitado. Um dos principais, ou mesmo, o principal pilar da ZDP é, por conseguinte, prejudicado no contexto da educação domiciliar, qual seja: a interação com o outro em situações intencionais de aprendizagem para o avanço da construção do conhecimento.

\section{Conclusões: um convite à reflexão}

Sem a pretensão de esgotar o tema e apresentar uma resposta definitiva às questões que se colocam em pauta acerca da educação domiciliar no Brasil, reiteramos nosso desejo em contribuir com o debate, fazendo um convite à reflexão. Essa reflexão não pode se furtar a lançar um olhar cuidadoso às questões educacionais mais amplas, dado que nos encontramos em um contexto em que as discussões acerca da educação domiciliar estão na ordem do dia e é iminente a construção de uma política educacional nesse sentido. Dentre as questões que se colocam para além das análises que fizemos ao longo do texto e sobre as quais pretendemos refletir em produções posteriores, estão: se a escola está longe de uma forma utópica idealizada, mesmo com todo o aparato de fiscalização e controle a que está sujeita, de que modo se buscará garantir que a educação domiciliar se dê de forma positiva e salutar para as crianças que nela estejam inseridas? Qual a formação e o conhecimento técnico daqueles que conduzirão os processos de educação domiciliar para que sejam respeitadas as demandas e as necessidades de aprendizagem da criança? Quem avaliará a efetividade desse processo extraescolar?

Neste artigo, buscamos estabelecer considerações sobre o ensino domiciliar (bomeschooling) e o contexto escolar, no que tange aos aspectos da diferença, da igualdade e da construção do conhecimento. Retomando a teoria de Vygotsky, apresentada neste artigo, ratificamos o entendimento do desenvolvimento humano e da aprendizagem como dois processos que se entrelaçam e se implicam. A escola, como espaço de diferenças, é um local potente para que a ZPD se torne a zona real de desenvolvimento, pela amplitude das interações, pela possibilidade da compreensão, pela testagem de distintas hipóteses e pela interação, que amplia e produz o entendimento de realidade. Seja no brincar, seja no compartilhar, no conviver, no aprender, a criança vai construindo a sua emancipação em relação às restrições situacionais que vive. Desse modo, quanto maior o seu contato com diferentes possibilidades, proporcionalmente aumentarse-á o estímulo para o desenvolvimento de habilidades mentais, fundamentais para a resolução de problemas de qualquer ordem.

Ainda sobre a teoria de Vygotsky, quanto ao entendimento da importância da fala no desenvolvimento de funções mentais superiores, considerando que as crianças, antes de controlarem o próprio comportamento, começam a controlar o ambiente com a ajuda da fala, novamente a interação e a amplitude dela, proporcionada pelo ambiente escolar, reforçam nossa tese de que a escola é um ambiente potencializador do desenvolvimento humano e da aprendizagem. Pela diferença, a criança é desafiada a argumentar, negociar, estabelecer limites, lidar com limites impostos, em um movimento de busca pelo pertencimento e pela constituição como sujeito, por meio das formas culturalmente vivenciadas.

Assim sendo, reconhecemos a escola como lócus privilegiado para o desenvolvimento socioemocional e cognitivo, a partir e com o outro. A escola não é perfeita em seu propósito, nem tampouco está acima das críticas. No entanto, nela, há uma rede de profissionais que, coletivamente, refletem e buscam aprimorar as ações por eles propostas. Dessa maneira, a criança que frequenta o espaço escolar pode contar com uma diversidade de olhares e de perspectivas que não haverá na intimidade do seu lar. A escola torna-se, portanto, um mundo de diversidades em que a criança amplia a aquisição da cultura e do seu próprio olhar, na medida em que outros olhares 
lhe são compartilhados. Desta forma, a escola não é reduzida a um espaço de socialização e de aquisição do conhecimento. A escola é um espaço de experiências e de existências.

\section{Referências}

BEAR, M. F.; CONNORS, B. W.; PARADISO, M. A. Neurociências: desvendando o sistema nervoso. Porto Alegre: Artmed, 2002.

BIESTA, G. Para além da aprendizagem: educação democrática para um futuro humano. Belo Horizonte: Autêntica, 2017.

BRASIL. Lei $N^{o}$ 8.069, de 13 de julho de 1990. Dispõe sobre o Estatuto da Criança e do Adolescente e dá outras providências. Diário Oficial da União: seção 1, Brasília, DF, n. 135, p. 13563, 16 jul. 1990.

BRASIL. Câmara dos Deputados. Educação domiciliar: prós e contras. TV Câmara, 2019a. Disponível em: <https://www.youtube.com/watch?v=fZ0EMETPMhQ>. Acesso em: 2 abr. 2020.

BRASIL. Projeto de Lei 2401, de 17 de abril 2019. Dispõe sobre o exercício do direito à educação domiciliar, altera a Lei no 8.069, de 13 de julho de 1990 - Estatuto da Criança e do Adolescente, e a Lei $\mathrm{n}^{\circ}$ 9.394, de 20 de dezembro de 1996, que estabelece as Diretrizes e Bases da Educação Nacional. Brasília: Câmara dos Deputados, [2019b]. Disponível em: $<$ https://www.camara.leg.br/proposicoesWeb/prop_mostrarintegra?codteor=1734553\&filenam $\mathrm{e}=\mathrm{PL}+2401 / 2019>$. Acesso em: 2 abr. 2020.

CASAGRANDE, C. A.; HERMANN, N. Formação e homeschooling: controvérsias. Práxis Educativa. Ponta Grossa, v. 15, p. 1-16, 2020. DOI: https://doi.org/10.5212/PraxEduc.v.15.14789.032

COSENZA, R. M.; GUERRA, L. B. Neurociência e educação: como o cérebro aprende. Porto Alegre: Artmed, 2011.

GADAMER, H. Verdade e método II: complementos e índice. Petrópolis: Vozes. Universidade São Francisco, 2002.

GUILHERME, A.; MORGAN, W. J. Philosophy, dialogue, and education: Nine Modern European Philosophers. New York: Routlegde, 2018.

LÓPEZ, M. V.; MASSCHELEIN, J.; SIMONS, M. Skholé e igualdade. In: LARROSA, J. (Org.). Elogio da escola. Belo Horizonte: Autêntica, 2017. p. 177-193.

MASSCHELEIN, J; SIMONS, M. Em defesa da escola: uma questão pública. Belo Horizonte: Autêntica, 2013.

ROSSA, A. A.; ROSSA, C. R. P. O aprendizado da leitura sob a perspectiva enatista: relações com a neurobiologia do sistema cerebral de recompensa. In: TREVISAN, A.; MOSQUERA, J. J. M.; PEREIRA, V. W. (orgs.). Alfabetização e Cognição. Porto Alegre: EdiPUCRS, 2011. p. 37-50.

VASCONCELOS, M. C. C.; BOTO, C. A educação domiciliar como alternativa a ser interrogada: problemas e propostas. Práxis Educativa, Ponta Grossa, v. 15, p. 1-21, 2020. DOI: https://doi.org/10.5212/PraxEduc.v15.14654.019 
Educação domiciliar, diferença e construção do conhecimento: contribuições para o debate

VYGOTSKY. L. S. A formação social da mente: o desenvolvimento dos processos psicológicos superiores. 7. ed. São Paulo: Martins Fontes, 2007.

Recebido em 24/01/2020

Versão corrigida recebida em 29/03/2020

Aceito em 30/03/2020

Publicado online em 06/04/2020 